\title{
PREVALENCE OF METABOLIC SYNDROME AMONG OBESE EGYPTIAN SCHOOL STUDENTS
}

\author{
N.E. Hasssan ${ }^{1}$, S.A. Elmasry ${ }^{1}$, W.A. Fouad ${ }^{2}$, L. Sherif ${ }^{3}$, A. Elwakkad ${ }^{4}$, M. Anwar ${ }^{4}$, S.T. Zaki ${ }^{3}$ \\ ${ }^{1}$ Biological Anthropology, ${ }^{2}$ Community Medicine, ${ }^{3}$ Child Health, ${ }^{4}$ Medical Biochemistry, National Research \\ Centre, Dokki, Giza, Egypt
}

Background: Egypt has experienced an increase in the prevalence of childhood overweight/obesity over last decades.

Aim of study was to assess prevalence of metabolic syndrome (MS) and other metabolic features among obese Egyptian school students.

Methods: Study included 462 obese students (body mass index $>95$ th percentile), 122 prepubertal and 340 pubertal, aged 7 - 18 years. Approved by Ethical Community, National Research Centre. Each subject was submitted to clinical, anthropometric and laboratory assessment. Diagnosis of hypertension, impaired fasting glucose, hyperinsulinieamia, insulin resistance(HOMA-IR), dyslipideamia and MS were defined according to Grundy (2004).

Results: MS was found in 39.7\%, with a significantly higher rate among prepubertal (45.5\%) than among pubertal students (37\%). Prevalence of MS was higher in girls than boys in pubertal age and total sample, while boys have higher prevalence in prepubertal age. Hypertension was significantly more common in pubertal $(22.3 \%)$ than prepubertal group (14.8\%) with obesity. Prevalence of impaired fasting glucose, hyperinsulineamia and HOMA-IR was 20.5, 13.6 and 13.6\% among prepubertal and 25.0, 3.3 and 22.8\% among pubertal, respectively. Prevalence of fasting hyperinsulinemia in prepubertal was significantly higher than pubertal, while prevalence of impaired fasting glucose and HOMA-IR in pubertal was significantly higher than prepubertal. Overall, dyslipideamia in prepubertal and pubertal was identified in 93.2 and $91.3 \%$, respectively, with significant differences.

Conclusions: MS prevalence among prepubertal is quite higher than pubertal students and in girls more than boys in Egypt, with abnormal lipid profiles, obesity and nutritional mistakes.

Acknowledgements: To National Research Centre, Egypt for funding this project. 